\title{
Problems in Cross-border E-commerce Export Trade in China \& Countermeasure Analysis
}

\author{
Yang Zhenhua ${ }^{1}$, \\ 1.Jiangxi Science and Technology Normal University, \\ Jiangxi, Nanchang197907
}

\begin{abstract}
As an emerging industry in China, cross-border e-commerce has enjoyed the leap-forward development, along with increasingly prominent problems. This paper aims at finding out the problems and related roots that hinder its development, through conducting an analysis on the export development of cross-border e-commerce, in order to look for solutions and countermeasures in favor of its sound development and to promote the liberalization development of foreign trade in China.
\end{abstract}

Key Words: Cross-border E-commerce Export; Cross-border Logistics; Cross-border E-commerce Supervision

\section{Introduction}

Traditional foreign trade export has been under the influence of labor force, resources and other factors with sluggish growth; under such background, internet featuring globalization and low cost has given rise to cross-border e-commerce to meet demands. Cross-border e-commerce, characterized by "all days, all directions and zero distance", has changed the original operation modes and rebuilt the industrial chain of foreign trade and provided new channels for enterprises' overseas marketing. The rapid emergence of cross-border e-commerce, represented by Aliexpress and eBay, relying on internet and international logistics, has broken through the original concept of "business district", lowered down the requirements for market access of foreign trade, reduced the number of links of foreign trade, upgraded the profit margin of foreign

\author{
Shen Qiang ${ }^{2}$ \\ 2.Nanchang University, \\ Jiangxi, Nanchang330031
}

trade, eliminated excessive profit, and been connected to terminals for multiple advantages, such as varied commodity information base, customized advertisement promotion, public consumer assessment, rapid propagation and convenient payment, aiming at meeting the demands of overseas terminal client, playing the immeasurable role in stabilizing the growth of foreign trade in China. Related policies issued by Ministry of Finance and National Taxation Bureau have clearly regulated that since January 2014, eligible cross-border e-commerce enterprises engaging in retailing export could also enjoy the rebate and exemption policies of value added tax and consumption tax. The introduction of this policy and supporting ones means the arrival of rapid development period for cross-border e-commerce export business in China and China's foreign trade entering into new era.

\section{Analysis on Development Status of Cross-border E-commerce Export Trade 2.1 Scale of Cross-border E-commerce Export Transaction}

In the recent years, cross-border e-commerce in China has finished its initiation and entered into the rapid development. According to the data of 2013 released by Commerce Department, at present, there have been over 5,000 cross-border e-commerce platforms in China, and over 200,000 enterprises conducting cross-border e-commerce via various platforms. 


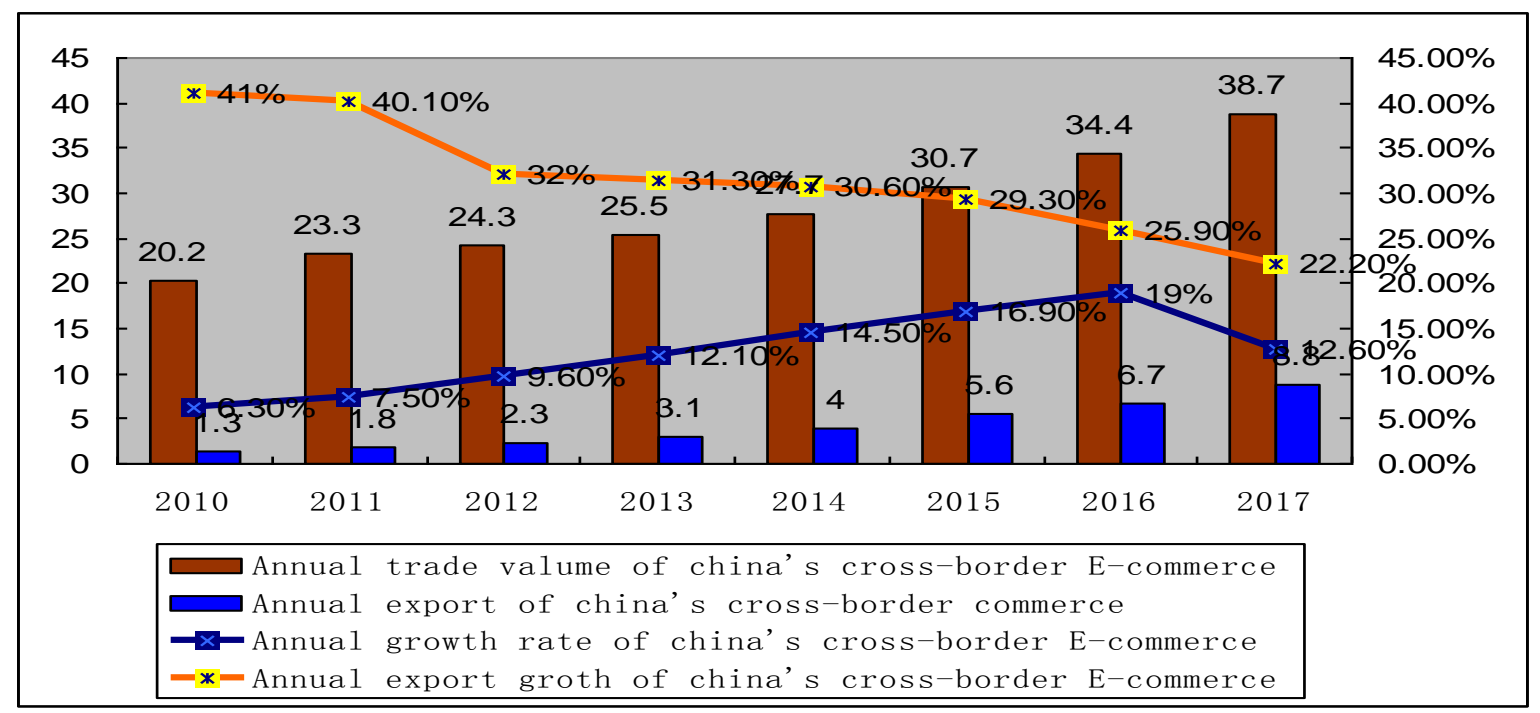

Fig 1: Annual Trade Volume, Export and Growth Prediction of China's Cross-border E-commerce in 2011-2018 (Unit: Trillion RMB)

\section{Data Resource: Data Integrated of 2014 Research Report on China's Cross-border E-commerce Industry and Computation Results of Ireserach Statistics Model}

Along with the emergence of $\mathrm{B} 2 \mathrm{~B}$ and $\mathrm{B} 2 \mathrm{c}$, e-commerce and the entire e-transaction industry have undergone rapid development with wider scales. In the first half of 2014, the transaction volume of China's cross-border e-commerce had been around RMB 3 trillion, among which RMB 300 billion was contributed by cross-border retailing business. In the wake of general trend of rapid development of global e-commerce industry and the issuance of national policies to encourage cross-border e-commerce, industrial participators' positive promotion and the rapid improvement of industrial chain, the transaction scale of China's cross-border e-commerce transaction will maintain the rapid development; and the proportion of e-commerce in China's import and export trade will be higher and expected to be $21.3 \%$ in 2018 , as shown in figure above.
By 2018, China's cross-border e-commerce transaction scale is expected to be around RMB 10 trillion. During the period between 2011 and 2018, this number can be increased from RMB 1.8 trillion to RMB 9.7 trillion, with an annual growth rate as $12 \%$.

According to figure below of import and export ratio, structure distribution and prediction 2010-2017 cross-border e-commerce in 2010-2017, proportion of export in 2010 was $93.5 \%$. It is predicted that this proportion will be decreased to $84.4 \%$ in 2017 . However undoubtedly, most trade volume of cross-border e-commerce is contributed by export e-commerce, with lower proportion of import e-commerce. Yet following the openness and infrastructure improvement of China's cross-border online shopping market, the proportion of import e-commerce will be gradually increased in the future. 


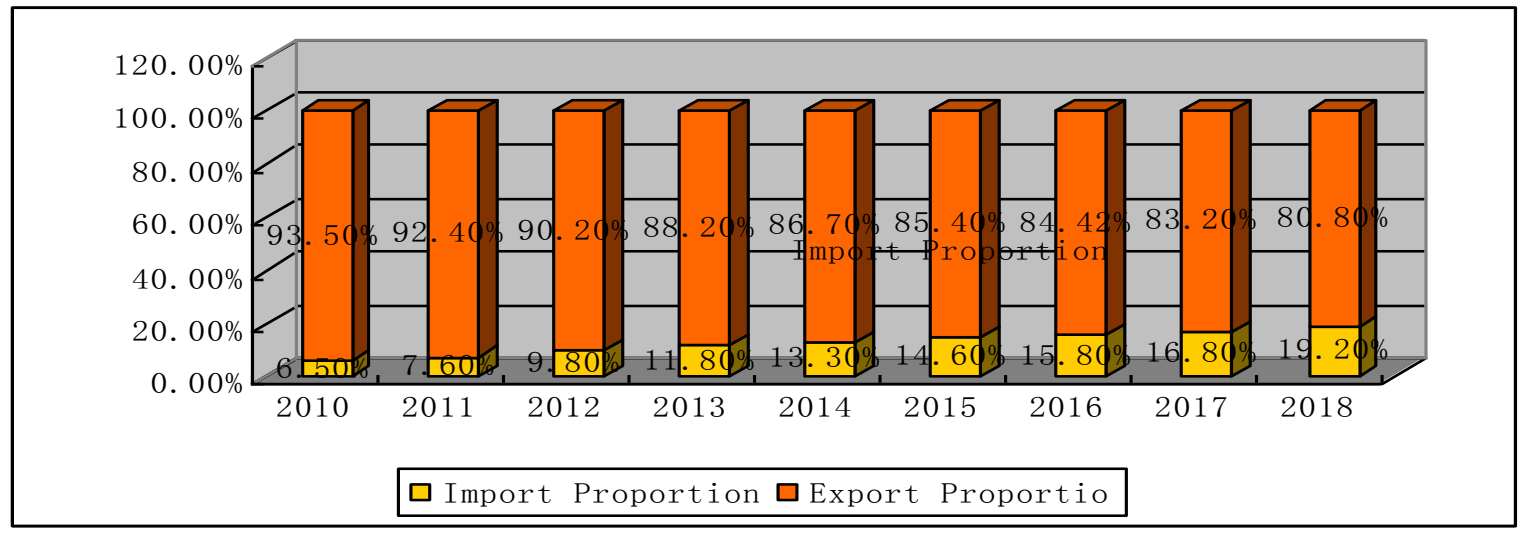

Fig 2: Ratio of China's Import and Export Cross-border E-commerce and Prediction Data Resources: Data Integrated of 2012China Statistical Yearbook and Computation Results of Ireserach Statistics Model

\subsection{Basic Procedure for Cross-border E-commerce Export}

The basic procedure of cross-border e-commerce normally includes the following steps: firstly, a manufacturer and a service provider shall register on third-party cross-border logistics platforms; after certification, they shall display their products or services on the platforms provided by cross-border e-commerce enterprises with marked titles, prices and modes of distribution. Cross-border e-commerce platforms can also conduct promotion and marketing of those products and services through those platforms, so that overseas purchasers can screen the products and services displayed on cross-border e-commerce platforms to order and make online payment via cross-border payment organizations; and payments shall be transferred to sellers' overseas accounts via online payment organizations or domestic accounts via banks. Secondly, the seller in China shall deliver related products to a cross-border logistics enterprise for distribution, which shall send those products to the custom of export place. At the same time, the cross-border e-commerce platform shall transfer the order, logistics and payment information it has collected to the custom clearance service platform of export place. This platform will summarize the Clearance List to clearance supervision platform. The clearance of any enterprise selecting China Post or international expresses can be made by logistics enterprises. After passing the custom examination and commodity inspection, local custom will conduct the examination and acceptance of real products and inform the logistic enterprise. In the end, products will be delivered to the custom of country of destination by the logistics enterprise and be distributed to the overseas buyer after custom clearance and commodity inspection. 


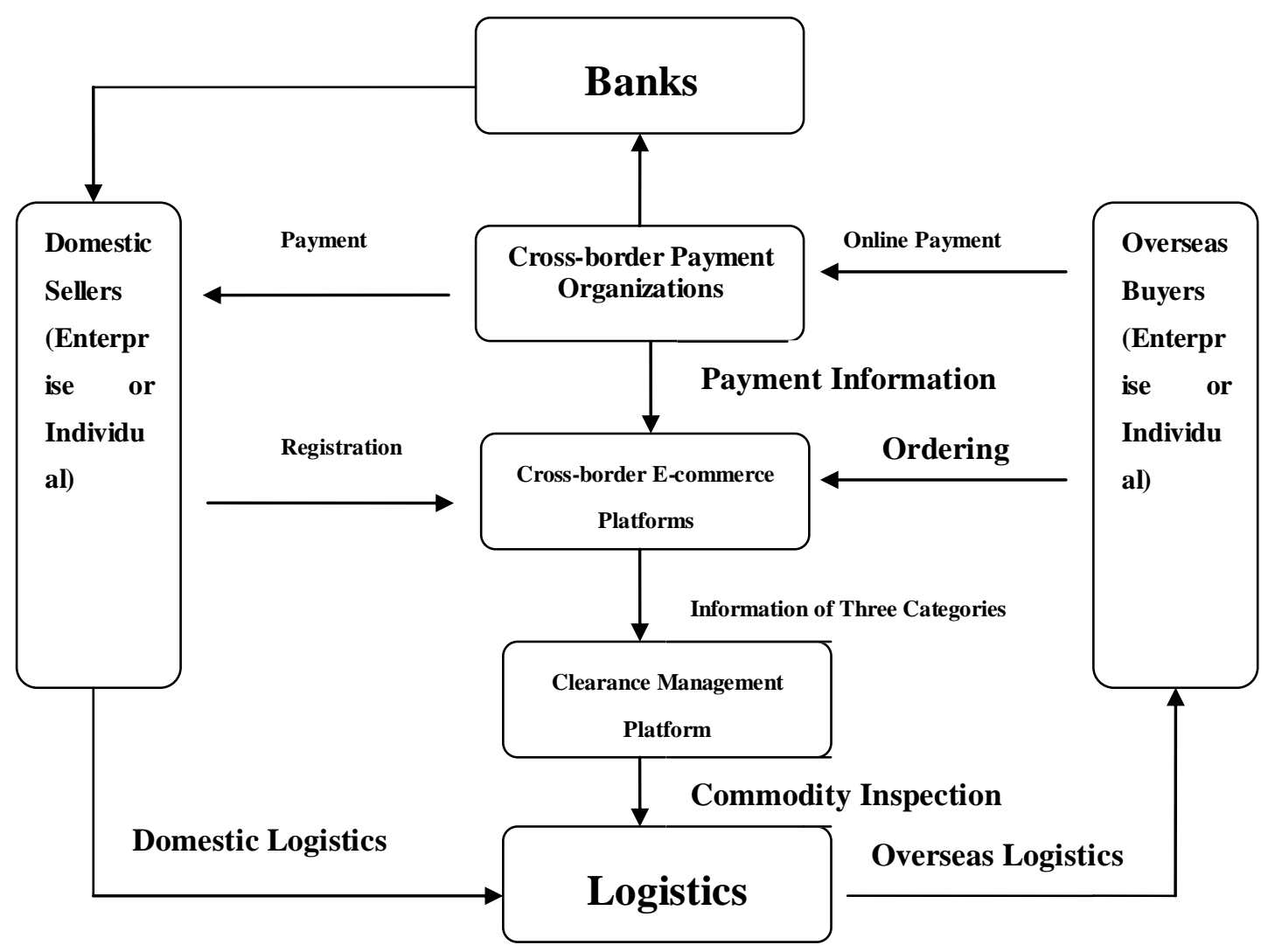

Fig 3 :Basic Mode of Cross-border E-commerce Export

\section{Problems Existing in Cross-border E-commerce}

\subsection{Time-consuming Logistics, Untraceable Packages and High Breakage/Loss Rate}

"Logistics can be the greatest problem for cross-border e-commerce," proposed by Mr. Wolfgang Bayer, CEO of Singapore Post Group, in First Session of International World Wide Web Conference in 2014. Compared to domestic logistics, cross-border e-commerce logistics is much more complicated and can be divided into four links: firstly, sellers shall put its products in the logistics storage of place of dispatch, which shall be delivered to custom bureau of place of dispatch by domestic logistics for clearance; secondly, custom bureau of place of dispatch shall deliver related products to local container yard for encasement and transport the containerized products to the port or airport of destiny through sea transportation or air transportation; thirdly, after arrival at destiny, products shall be delivered to the reserved overseas warehouses or any warehouses of local logistics providers after customs clearance; fourthly, overseas logistics providers shall deliver the products to customers. The entire logistics links are complicated and tedious; and the extreme different policies in various countries have led to a series of problems existing in cross-border e-commerce logistics. First of all, the logistics and delivery process is time consuming, with packages unable to be traced and inquired in the full course. Secondly, changing or refunding is impracticable. Cross-border e-commerce logistics shall pass through two customs barriers, namely export declaration and import clearance, with commodity inspection involved, complicated procedures and expensive expenditures. Thirdly, packages' breakage and loss rates are far 
higher than those of domestic e-commerce logistics.

\subsection{Difficulties in Cross-border Clearance, Commodity Inspection, Payment, Exchange Settlement and Tax Rebate}

The first difficulty is clearance. And this problem exists in both B2C and B2B of small amount. Traditional cross-border trade clearance is the clearance of a large amount of commodities, featuring long cycle and high expenditure. However, this mode is not suitable for cross-border e-commerce clearance. The commodities of cross-border e-commerce feature small amount, high frequency and disparity; consequently, cross-border e-commerce clearance features shorter cycle and lower expenditure. The second difficulty is commodity inspection. At present, the commodity inspection is mainly designed for traditional cross-border trade, making it not appropriate for cross-border e-commerce featuring wide sources, more batches and small volumes and difficult to require cross-border e-commerce enterprises to accept inspections. The third difficulty is unsmooth export exchange settlement. Many of cross-border e-commerce enterprises or sellers are not qualified for traditional cross-border trade, making them unable to conduct the normal foreign exchange verification and receipt and payment. Therefore, those enterprises or sellers are forced to apply abnormal ways for exchange settlement, leading to the extremely unsmooth link of exchange settlement in the entire system.

\subsection{Imperfect Industrial Credit, Absence of Supervision and Difficulty in Solving Transaction Disputes}

In cross-border e-commerce industry, the credit problems are especially prominent. Currently, the access mechanism of cross-border e-commerce is very loose; the identities of commercial tenants are verified by commercial platforms with incompletely translucent information sources, leading to many of small dealers or individuals entering into the platforms without business licenses; the quality of commodities on the platforms are unable to be supervised, and quality problems can only be handled afterwards.

Industrial supervision is absent. There have been no specified regulations and standards regulated by Chinese government for cross-border e-commerce transactions from the perspectives of competition, taxation and consumption disputes. The problem of unfair competition in cross-border e-commerce transactions is very prominent, e.g. false promotion by virtue of cross-border e-commerce platforms, attacking competitors, spreading false information, selling forged and fake commodities, stealing user information, fraud and other illegal behaviors that lead to the successive complaints of overseas buyers.

It is very hard to solve transaction disputes of cross-border e-commerce, which are very different from those of traditionally cross-border commercial transactions. You can imagine that one overseas buyer purchases a woolen sweater valued couples of dollars from a seller in China via eBay, he/she will find it very difficult to solve the dispute through traditional judicial proceedings featuring complicated process, expensive cost and time consumption; therefore, the legitimate rights and interests of this overseas buyer will be difficult to be maintained.

\section{Countermeasure Analysis of Cross-border E-commerce Export Problems}

\subsection{Countermeasures for Time-consuming} Logistics, Untraceable Packages and High Breakage/Loss Rate

The cross-border logistics approaches include four modes: China Post, international express, special-line logistics and overseas storage, which are characterized by their own features. China Post features untraceable packages, huge price fluctuation, high breakage and loss rate and relatively cheaper costs; international expresses features faster speed of delivery and clearance with higher cost; special-line logistics features rapid speed and cheaper cost, but narrower coverage and rejection of refund; overseas storage features extremely rapid speed, traceable packages, 
acceptance of changing or refunding but difficult storage management and higher up-front investment. The cross-border logistics modes mentioned above have their own advantages and disadvantages. Therefore, when choosing logistics, sellers of e-commerce transactions shall be based on their own transaction scales, market and strengths. Generally speaking, sellers with large transaction scale, diversified market and strong strength shall build up their own overseas storages. While sellers with small transaction volume and centralized market shall choose the special-line logistics of e-commerce platforms to lower down its logistics cost. And small-scale sellers can also take advantage of the special-line logistics channels of e-commerce platforms to deliver their commodities to warehouses at overseas ports of the platforms, and the delivery will be completed by the overseas warehouse information platforms of cross-border e-commerce. At the same time, cross-border e-commerce enterprises located in Shanghai, Shenzhen and other centralized manufacturing and commercial regions can join hands together to organize a logistics union, in order to negotiate with international logistics enterprises, conclude logistics agreements, formulate special logistics routes, enjoy special-line logistics service and freight discount, cooperate with fourth-party logistics enterprises, strengthen the supervision on logistics process, timely track logistics information and manage commodity changing and refund.

\subsection{Countermeasures of Difficulties in Cross-border Clearance, Commodity Inspection, Payment, Exchange Settlement}

Since October 2013, multiple provinces and cities in China have been positively exploring new modes of cross-border e-commerce commercial services and building up new platforms, in order to solve problems of difficulties in clearance, commodity inspection, payment, exchange settlement and tax rebate of cross-border e-commerce. The first problem is clearance. A model of "verification and passing based on detailed lists and collective declaration" has been applied in pilot cities. Local customs shall make rapid verification of commodities based on the "electronic lists" reported by enterprises. After commodities leaving the exporting country, enterprises shall summarize the "electronic lists" into customs declarations for export commodities on a regular basis. E-commerce enterprises shall firstly follow the lists for clearance; then, customs clearance system will summarize the lists on a regular basis to form customs declarations for reporting and declaration, in order to prevent e-commerce enterprises from a large amount of daily declarations. The second difficulty is commercial inspection. Pilot cities normally "conduct inspection and quarantine recording for e-commerce export enterprises and related products or access management", take advantage of third-party inspection and identification institutions to conduct the conformity assessment on product quality and safety. Full-declaration system is implemented focusing on quarantine and supervision, with no statutory inspection for normal manufactured goods. The convenient measures of centralized declaration and proceeding of related inspection and quarantine are mainly to solve the commodity inspection problems of most of e-commerce enterprises. Thirdly, related national ministries and commissions are planning to implement a more effective exchange settlement method for cross-border e-commerce industry, cancel the classified management of foreign trade enterprises; and confirm the necessary effective documents for enterprises' exchange settlement and the verification of third-party institutions; enterprises shall just apply for exchange settlement based on their own demands.

\subsection{Countermeasures of Imperfect Industrial Credit, Absence of Supervision and Difficulty in Solving Transaction Disputes}

In order to realize the rapid development of cross-border e-commerce and adapt the scale 
development of industry, China shall make the systematic construction of cross-border e-commerce credit system. Firstly, China shall complete and improve related laws of cross-border e-commerce credit, confirm the legal responsibilities of various parties, prevent illegal behaviors of service providers and traders to ensure the good-faith management. Secondly, China shall complete the client credit management and transaction credit assessment institution, build up a public credit service platform; provide credit services for clients, including information inquiry of identities, credit, credit assessment and other information of e-commerce enterprises. Thirdly, China shall implement strict access examination for cross-border e-commerce platforms, implement the identity institutions of e-commerce subjects, implement measures of credit assessment, payment certification and violation off-limits, to ensure the sustainable development of cross-border e-commerce.

China shall strengthen the supervision on cross-border e-commerce enterprises; market supervision institutions shall strictly investigate and treat any behaviors of production and distribution of counterfeited products, selling seconds at best quality prices, releasing false advertising, breaking contracts or other fraudulent conducts. At present, the most suitable way to solve consumers' cross-border e-commerce disputes is believed to be online arbitration and negotiation; parties involved of cross-border e-commerce can solve their disputes through the internet directly, to save time and expenditure cost and to improve the efficiency.

\section{Conclusion}

In conclusion, there are a lot of problems and governance vacuum existing in cross-border e-commerce export. However, they will never hinder the irresistible trend of the international trade development of cross-border e-commerce. It has integrated the links of clearance, commodity inspection, transaction, logistics, exchange settlement and tax rebate through foreign trade network to form a complete and smooth supply chain of internet export sales, opening a new road for domestic enterprises to enjoy their shares in international market. Therefore, I believe that Chinese cross-border e-commerce export enterprises will solve various difficulties in front of multiple barriers to make outstanding contributions for the soundly sustainable development of the entire national economy.

\section{Reference:}

[1].CEO of Singapore Post Group: Green Channels shall be arranged for the convenience of cross-border e-commerce" [N]. National Business Daily, 2014-11-21.

[2].Wang Kaiqian. Barrier Factors and Next Steps for Cross-border E-commerce Development Status in China [J] Revolution, 2014-05-15.

[3].BLOCK Rule for Cross-border E-commerce: Branding + Localization + Full Channel[EB/OL] http://www.cifnews.com/, 2014-09-16.

[4]. Summary of Pilot Policies of Cross-border E-commerce in Six Chinese Cities in 2014. [EB/OL] http://www.cifnews.com/, 2014-12-30.

[5]. Unveiled Cross-border E-commerce Mode in Qingdao and Refundable Retailing Export [N]. Qingdao Financial Daily, 2014-06-30.

[6]. Wang Zong, Ma Qing, Liu Tie. Analysis on Small-amount Cross-border E-commerce [J], Value Engineering, 2012, (11): 180-181. 